\title{
Additive interaction of snoring and body mass index on the prevalence of metabolic syndrome among Chinese coal mine employees: a cross-sectional study
}

\author{
Yanyan Li ${ }^{1}$, Qian Gao ${ }^{1}$, Lu Li ${ }^{1}$, Yanan Shen ${ }^{1}$, Qing Lu, ${ }^{1,4}$ Jianjun Huang ${ }^{2}$, Chenming Sun ${ }^{3}$, Hui Wang ${ }^{1}$, Nan Qiao ${ }^{1}$,
} Cong Wang ${ }^{1}$, Haixia Zhang ${ }^{1}$ and Tong Wang ${ }^{1 *}$

\begin{abstract}
Background: Although snoring has been previously reported to be associated with metabolic syndrome (MetS), its interaction with body mass index(BMI) on MetS remains unclear. We aimed to examine the individual effects and possible interaction between snoring and BMI on MetS.

Methods: From July 2013 to December 2013, 3794 employees of coal mining enterprises aged 18 to 65 were recruited from Shanxi province of China. The individual effects were assessed by multivariable logistic regression model. Additive interaction was evaluated by calculating the relative excess risk due to interaction (RERI), attributable proportion due to interaction (AP) and synergy index(S).

Results: We found that, after adjusting for potential confounders, odds ratio (OR) and $95 \% \mathrm{Cl}$ for MetS was 1.30 $(1.09,1.56)$ in occasional snorers and $1.50(1.24,1.82)$ in habitual snorers compared with non-snorers. BMI $\geq 24$ was related to high risk of MetS $(\mathrm{OR}, 3.27 ; 95 \% \mathrm{Cl}, 2.93-3.63)$. Significant additive interaction between snoring and $\mathrm{BMl}$ on MetS was detected. The estimates and $95 \% \mathrm{Cl}$ of the RERI, AP and S were $1.89(0.67,3.24), 0.23(0.08,0.38)$, and $1.37(1.11,1.75)$, respectively. However, stratified by workplace, the additive interaction was only significant among underground front-line and ground workers.
\end{abstract}

Conclusions: Both Snoring and BMI were related to high risk of Mets. Moreover, there are additive interaction between snoring and BMI. Snorers who worked underground front-line and ground are more susceptible to the negative impact of being overweight on MetS.

Keywords: Snoring, BMI, MetS, Additive interaction, Workplace

\section{Background}

Metabolic syndrome, a cluster of metabolic disorders including obesity, high blood pressure, dyslipidemia, and hyperglycemia, is considered to be a risk factor for numerous chronic diseases, such as diabetes, kidney disease, cardiovascular disease, prostatic hyperplasia and subsequent disease-related mortality [1-3]. Given that the prevalence of MetS is increasing in both developed

\footnotetext{
* Correspondence: tongwang@sxmu.edu.cn

1Department of Health Statistics, School of Public Health, Shanxi Medical University, 56 Xinjiannanlu Street, Taiyuan, Shanxi 030001, People's Republic of China

Full list of author information is available at the end of the article
}

and developing countries and MetS has become a worldwide serious public health problem, identifying simple, feasible and modifiable indicators for screen high-risk group is of critical importance [4, 5]. For high-risk population, we can implement the targeted interventions. It is in conformity with the concept of precision medicine. Coal mine employees, especially the underground front-line workers, exposure to long-term high-risk environment. They are constantly threatened by productive dust (coal dust, silica dust and mixed dust), harmful physical factors (noises, vibration, hot and humid environments), productive poisons and other factors (lead, benzene and trinitrotoluene) [6]. Poor 
production environment, shift work and frequent coal mine accidents in recent years have led to the occupational stress in coal mine employees. The above factors increase the risk of metabolic syndrome and lead to higher prevalence of metabolic syndrome in coal mine employees than the general population [7]. The potentially useful biomarkers of MetS, play a more valuable role in coal mine employees than in the general population. So we aim to identify indicators of MetS among coal mine employees.

Measuring snoring, a manifestation of obstructive sleep apnea (OSA) syndrome, is easy, low-cost and noninvasive. Cumulative epidemiological data demonstrated that habitual snoring was associated with cardiovascular events [8,9], hypertension [10], and diabetes [11]. While several studies that focused on the general population have shown that snoring was also strongly related to MetS [12-18]. The association between snoring and MetS is still unknown in coal mine employees. Therefore, in this study we first explored whether the relationship is significant in coal mine employees.

In addition, obesity is a modifiable risk factor of MetS and can be improved through diet control and physical activities. Thus, obesity may be a critical aspect of prevention and management of MetS. Plenty of established evidence have shown that BMI is strongly associated with MetS $[19,20]$.

Although the exact mechanisms of snoring and BMI on MetS are not fully elucidated, several explanations for the association have been suggested. Hypoxia and hypercapnia induced by snoring stimulate sympathetic nervous activity [21] and increase plasma catecholamine levels [22], which consequently lead to insulin resistance and metabolic disorders [23]. Adipose tissue is a highly active endocrine organ that releases a range of adipokines and promotes expression of inflammatory markers. These inflammatory markers maybe mediate the detrimental effect of obesity on the development of MetS [24].

Based on the above mechanisms, it is plausible to suppose that snoring give rise to the risk of obesity. First, due to the impaired metabolism, snoring may itself predispose individuals to worsening obesity. Furthermore, snoring is the main symptom of OSA. OSA may be associated with changes in hormone level, such as leptin [25], ghrelin [26], and orexin [27]. These hormones can cause increased appetite and calorie intake, thereby promoting obesity. Conversely, obesity also seem to cause and aggravate snoring. Fat deposition in the upper airway lumen and muscle could reduce tracheal traction and lung volume, resulting in the obstruction of upper airway [28]. Thus, it appears that snoring and obesity form a vicious cycle where one results in worsening of the other. In epidemiology, interaction refers to the situation where the effect of one risk factor on a certain disease outcome is different across strata of another risk factor. The joint effect of two factors is not equal to the sum (additive interaction) or the product (multiplication interaction) of individual effect [29]. Therefore, it could be reasonable for us to guess that there is an interaction between snoring and obesity. That is to say, the coexistence of snoring and BMI may synergistically cause MetS.

So far, only one study conducted in a healthy population from China has reported the combined effect of snoring and BMI on MetS [17]. The research found the multiplicative interaction between snoring and BMI in relation to MetS does not exist. However, the absence of multiplicative interaction doesn't mean there is no additive interaction [29]. Little information about the additive interaction is known. Andersson et al. suggested that we should focus on additive rather than multiplicative interaction when a biologic interaction is examined [30]. Considering additive interaction is more closely relevant to prevention and risk prediction of diseases, we decided to examine whether the additive interaction between snoring and BMI exist.

Furthermore, long-term occupational exposure, such as coal dust, may affect the worker's airway conditions and lipid metabolism [31]. And workers in different workplace were exposed to different occupational risk factors. Therefore, this study also aimed to explore whether the result of additive interaction is consistent among coal mine employees in different workplace.

\section{Methods}

\section{Study population}

The study subjects were recruited from a large coalmine population with more than 200,000 samples in Shanxi Province of China, from July 2013 to December 2013. This survey was conducted with a two-stage cluster stratified population sampling method. In the first stage, ten coalmines were randomly selected from 87 coalmines. We got the list of the 87 coalmines from general Hospital of Datong Coal Mining Group. All of the 10 coalmines that randomly drew from the list agreed to join our study and we got the informed consent from management of the coalmines. In the second stage of sampling, employees of coal mining enterprises were selected by the stratified random sampling method based on the baseline data including date of birth, gender, and work type, which were provided by the management of the coalmine group.

The sample size was computed according to the following formula:

$$
n=U^{2} \pi(1-\pi) / \delta^{2}
$$




$$
\begin{aligned}
& n_{c}=\frac{n}{1+n / N} \\
& n_{c}=3755
\end{aligned}
$$

Where, $U$ is the two-tailed standard normal variate value related to the null hypothesis, and $\pi$ is prevalence of MetS, $\delta$ is allowable error. $N$ is the population of the coal mine. Considering the expected prevalence of MetS of $33.9 \%$ [32], type I error of 0.05 , allowable error of $0.015,3755$ subjects would be necessary for the study. Taking no response from some subjects or other non-conforming situations into consideration, we aimed to survey 4600 coal mine employees. Among these individuals, 4298 subjects agreed and completed the study, for a response rate of $93.43 \%$. Besides, five hundred and four subjects who had missing values for variables of interest were excluded from the main analysis, and missing data were filled with multiple imputation (MI) method to conduct the sensitivity analysis.

\section{Assessment of snoring and related factors}

This survey was conducted by face-to-face interviews and by well-trained interviewers with medical knowledge. The questionnaires in our study consisted of questions on demographics, lifestyle and medical history factors. Snoring status was obtained from the question "Have you ever snored during sleep?" with three choices ("never", "occasionally", "habitually"). "Occasionally" refers to 1-2 days per week; "habitually" refers to $\geq 3$ days per week. This question is answered by the participants themselves or with the assistance of their families. The following variables were assessed by three categories: family income ( $\leq 4000,4000-6000, \geq 6000 \mathrm{CNY} /$ month), educational level (bachelor degree or above, junior college and senior high school, and junior high school or below), marital status (single, married and divorced), work type (heavy physical, light physical, and mental labor). Current smoking and alcohol consumption were defined as binary variables (yes, no). The international physical activity questionnaire (IPAQ) was used to assess the physical activity level. Physical activity level was grouped as inactive, minimally active and health-enhancing physical activity [33]. Workplace was grouped as underground front-line, underground auxiliary, ground and office. Underground front-line work includes machinery driving, manuals driving, artillery mining and reserves. Underground auxiliary mainly includes preliminary safety checking, ventilation, and recovery maintenance. Ground work includes transportation, communication, operation management and power supply. Office work includes human resources, administration and other supporting departments.

\section{Anthropometrics variables and biochemical variables}

The anthropometrics variables including height, body weight and waist circumference were measured multiple times by trained and certified examiners to ensure accuracy. Participants were lightly dressed without shoes when height and body weight were measured. The measuring accuracy for height and weight were $0.1 \mathrm{~cm}, 0.1 \mathrm{~kg}$, respectively. BMI was calculated as weight $(\mathrm{kg})$ divided by height squared $\left(\mathrm{m}^{2}\right)$ and was classified to 2 categories $(\mathrm{BMI}<24 ; \mathrm{BMI} \geq 24)$. Waist circumference (WC) was measured to the nearest $0.1 \mathrm{~cm}$ at the midpoint between the lowest rib margin and the iliac crest during expiration [34]. Participants' blood pressure was measured on the right upper arm, using a standard mercury sphygmomanometer by the nursing staff. Both systolic blood pressure (SBP) and diastolic blood pressure (DBP) were measured 3 times at 2-min intervals with study subjects in the sitting position after resting for $5 \mathrm{~min}$.

Blood samples taken from the antecubital vein were collected in the morning after a 10-h overnight fast. Concentrations of TG, HDL-C and fasting plasma glucose were measured by the SIEMENS ADVIA 1800 Automatic Biochemical analyzer (JEOL Ltd., Tokyo, Japan).

\section{Definition of metabolic syndrome}

MetS was defined by the harmonized criteria recommended by the 2009 International Diabetes Federation (IDF). According to the criteria, reaching any three of the following five factors will be diagnosed as MetS: (1) elevated TG: $\geq 1.7 \mathrm{mmol} / \mathrm{L}$; (2) high blood pressure: $\geq 130 / 85 \mathrm{mmHg}$; (3) $\mathrm{T}_{2} \mathrm{DM}$ or fasting plasma glucose: $\geq 5.6 \mathrm{mmol} / \mathrm{L}$; (4) reduced HDL-C: $<1.0 \mathrm{mmol} / \mathrm{L}$ (men) and $<1.3 \mathrm{mmol} / \mathrm{L}$ (women); and (5) elevated waist circumference(WC):WC $\geq 85 \mathrm{~cm}$ and $80 \mathrm{~cm}$ in Chinese men and women, respectively [35].

\section{Statistical analysis}

All data were double-entered into Epi info version 3.5.1 (CDC, Atlanta, USA) to reduce potential errors when we prepared the dataset for statistical analysis. All general characteristics were categorical data, which were described by frequencies and percentages. The univariate logistic regression was used to examine the relationship between independent variables and MetS. Crude odds ratios (cORs) and 95\% confidence intervals (95\% CI) were calculated. The effects of snoring status and BMI on metabolic syndrome were analyzed, using two different multiple logistic regression models. The first model was adjusted for age and sex. Besides age and sex, the second model was also adjusted for current smoking, alcohol consumption, marital status, physical activity level, educational level, monthly income, and work type. When exploring the relationship between snoring and 
Table 1 Characteristics of the study population and their association with MetS

\begin{tabular}{|c|c|c|c|c|}
\hline \multirow[t]{2}{*}{ Characteristics } & \multicolumn{2}{|l|}{ Mets } & \multirow[t]{2}{*}{ OR } & \multirow[t]{2}{*}{$P$ value } \\
\hline & Yes (1475) & No (2319) & & \\
\hline \multicolumn{5}{|l|}{ Gender, $n(\%)$} \\
\hline Men & $1306(88.54)$ & $1891(81.54)$ & $1.75(1.44,2.12)$ & $<0.001^{*}$ \\
\hline Women & $169(11.46)$ & $428(18.46)$ & & \\
\hline Age & & & $1.42(1.31,1.55)$ & $<0.001^{*}$ \\
\hline$\leq 35$ & $296(20.07)$ & $679(29.28)$ & & \\
\hline $35-45$ & $502(34.03)$ & $855(36.87)$ & & \\
\hline$\geq 45$ & $677(45.90)$ & $785(33.85)$ & & \\
\hline Monthly income (CNY), n (\%) & & & $0.91(0.84,0.99)$ & $0.039^{*}$ \\
\hline$\leq 4000$ & $416(28.20)$ & $573(24.71)$ & & \\
\hline $4000-6000$ & $625(42.37)$ & $1025(44.20)$ & & \\
\hline$\geq 6000$ & $434(29.42)$ & $721(31.09)$ & & \\
\hline \multicolumn{5}{|l|}{ Marital status, $n(\%)$} \\
\hline Single & $36(2.44)$ & $142(6.12)$ & 1 (reference) & \\
\hline Married & 1415 (95.93) & $2136(92.11)$ & $2.61(1.80,3.79)$ & $<0.001^{*}$ \\
\hline Divorced & $24(1.63)$ & $41(1.77)$ & $2.31(1.24,4.30)$ & $0.008^{*}$ \\
\hline \multicolumn{5}{|l|}{ Educational level, n(\%) } \\
\hline Junior high school or below & $420(28.47)$ & $627(27.04)$ & 1 (reference) & \\
\hline Bachelor degree or above & $172(11.66)$ & $280(12.07)$ & $0.92(0.73,1.15)$ & 0.453 \\
\hline Junior college and senior high school & $883(59.86)$ & $1412(60.89)$ & $0.93(0.80,1.08)$ & 0.366 \\
\hline \multicolumn{5}{|l|}{ Work type, $n(\%)$} \\
\hline Heavy physical & $316(21.42)$ & $654(28.20)$ & 1 (reference) & \\
\hline Light physical & $795(53.90)$ & $1076(46.40)$ & $1.53(1.30,1.80)$ & $<0.001^{*}$ \\
\hline Mental labor & $364(24.68)$ & $589(25.40)$ & $1.28(1.06,1.54)$ & $0.010^{*}$ \\
\hline \multicolumn{5}{|l|}{ Current smoking, $n(\%)$} \\
\hline Yes & $875(59.32)$ & $1293(55.76)$ & $1.16(1.01,1.32)$ & $0.031^{*}$ \\
\hline No & $600(40.68)$ & $1026(44.24)$ & & \\
\hline \multicolumn{5}{|l|}{ Alcohol consumption, $n(\%)$} \\
\hline Yes & $676(45.83)$ & $886(38.21)$ & $1.37(1.20,1.56)$ & $<0.001^{*}$ \\
\hline No & $799(54.17)$ & $1433(61.79)$ & & \\
\hline \multicolumn{5}{|l|}{ Physical activity level, $n$ (\%) } \\
\hline Inactive & $134(9.08)$ & $161(6.94)$ & 1 (reference) & \\
\hline Minimally Active & $452(30.64)$ & $657(28.33)$ & $0.83(0.64,1.07)$ & 0.149 \\
\hline Health-enhancing physical activity & $889(60.27)$ & $1501(64.73)$ & $0.71(0.56,0.91)$ & $0.006^{*}$ \\
\hline \multicolumn{5}{|l|}{ Workplace } \\
\hline Underground front-line & $237(16.07)$ & $525(22.64)$ & 1 (reference) & \\
\hline Underground auxiliary & $538(36.47)$ & $792(34.15)$ & $1.51(1.25,1.82)$ & $<0.001^{*}$ \\
\hline Ground worker & 421 (28.54) & $561(24.19)$ & $1.66(1.36,2.03)$ & $<0.001^{*}$ \\
\hline Office worker & 279 (18.91) & 441 (19.01) & $1.56(1.21,2.00)$ & 0.139 \\
\hline \multicolumn{5}{|l|}{ Snoring, n (\%) } \\
\hline Never & 375 (25.42) & $960(41.40)$ & 1 (reference) & \\
\hline Occasionally & $556(37.69)$ & 864 (37.26) & $1.65(1.40,1.93)$ & $<0.001^{*}$ \\
\hline Habitually & 544 (36.88) & 495 (21.35) & $2.81(2.37,3.34)$ & $<0.001^{*}$ \\
\hline
\end{tabular}


Table 1 Characteristics of the study population and their association with MetS (Continued)

\begin{tabular}{llll}
\hline Characteristics & Mets & OR & $P$ value \\
\cline { 2 - 3 } & Yes (1475) & & \\
\hline BMI (kg/ m2), $n(\%)$ & $1305(56.27)$ & $269(18.24)$ & \\
$<24$ & $1014(43.73)$ & $1206(81.76)$ & $5.77(4.94,6.74)$ \\
\hline 24 & & & $<0.001^{*}$ \\
\hline
\end{tabular}

Mets metabolic syndrome

*is used to highlight statistically significant $(p<0.05)$ findings

Mets components, the univariate and multiple logistic regression models were used. The aforementioned analyses were performed using PROC LOGISTIC in SAS 9.2 software (SAS Institute, Inc., Cary, NC, USA). Variance inflation factor (VIF) was used to assess potential collinearity among variables.

The additive interaction between snoring(no vs. yes) and $\operatorname{BMI}\left(<24\right.$ vs. $\left.\geq 24 \mathrm{~kg} / \mathrm{m}^{2}\right)$ was evaluated by three measures: relative excess risk due to interaction (RERI), attributable proportion (AP) and synergy index (S) [30, 36]. In this study, we took the "both non-snorers and $\mathrm{BMI}<24$ " as the reference group, $\mathrm{OR}_{11}$ refers to the effect of Mets for snorers whose $\mathrm{BMI} \geq 24$; $\mathrm{OR}_{10}$ represents the effect of Mets for non-snorers whose BMI $\geq 24$; while $\mathrm{OR}_{01}$ is the effect for snorers whose $\mathrm{BMI}<24$. Then, RERI $=\mathrm{OR}_{11}-\mathrm{OR}_{10^{-}} \mathrm{OR}_{01}+1 ; \mathrm{AP}=\mathrm{RERI} / \mathrm{OR}_{11} ; \mathrm{S}$ $=\left(\mathrm{OR}_{11}-1\right) /\left[\left(\mathrm{OR}_{01}-1\right)+\left(\mathrm{OR}_{10}-1\right)\right]$. We adopted the bootstrap percentile method which was presented by Knol et al. to calculate the corresponding 95\% CI for the estimates of interaction [19]. If there was no additive interaction, the $95 \%$ CI of RERI and AP would include 0, whereas $95 \%$ CI of S would contain 1. R 3.2.3 was used to carry out the bootstrap procedure. In this analysis, all tests were 2 -sided, and a $P$-value of $<0.05$ was considered statistically significant.

\section{Result}

\section{Characteristics of the study population}

The prevalence of MetS in this study was $38.88 \%$. The proportion of occasional and habitual snoring in the study were 37.35 and $27.39 \%$, respectively. Over half (58.51\%) of individuals were either overweight or obese. According to the results of univariate logistic regression analysis, all independent variables except educational level were related to the prevalence of MetS (see Table 1).

\section{Association between snoring and MetS}

The association between snoring and Mets is shown in Table 2. There was no evidence of multi-collinearity as all VIF values were less than 10 . For both multiple logistic regression models with different covariates adjustment, we found snoring is strongly associated with MetS and the risk of MetS increased progressively according to snoring status. In model 1 , the ORs for MetS were
$1.64(1.39,1.92)$ in occasional snorers and $2.50(2.10$, 2.97) in habitual snorers compared with non-snorers. However, with additional adjustment for current smoking, alcohol consumption, marital status, physical activity level, monthly income, work type, and BMI, the ORs of MetS for snorers were attenuated but remained significant for occasional snoring (OR, 1.31; 95\% CI, 1.091.56) and habitual snoring (OR, 1.50; 95\% CI, 1.241.82). We also explored the association between snoring and MetS using two multiple logistic regression models, which included snoring as binary variable. The OR of MetS for individuals with snoring was $1.38(1.17,1.62)$, compared with non-snorers.

\section{Association between snoring and MetS components}

The associations between snoring and MetS components are shown in Table 3. The prevalence of MetS components increased gradually according to snoring status in both univariate and multiple logistic regression models. After further adjusted for additional confounding factors, the association between snoring and high blood pressure, elevated fasting glucose, hypertriglyceridemia, abdominal obesity were attenuated but remained significant. However, the association with low HDL was no longer significant.

\section{Association between $\mathrm{BMI}$ and MetS/MetS components}

Our study indicated that BMI was strongly related to MetS. As shown in Table 1, the crude OR between BMI and MetS was 5.77 (4.94, 6.74). If additional covariates, significant in table1, were further adjusted, the OR for BMI reduced to $5.18(4.41,6.08)$. BMI's association with high blood pressure, elevated fasting glucose, hypertriglyceridemia, low HDL and abdominal obesity were significant (see Table 3).

\section{The additive interaction between snoring and BMI}

Participants were divided into 4 subgroups according to snoring and BMI level (Table 4). Compared with non-snorers with $\mathrm{BMI}<24$, the multi-adjusted ORs were $5.57(4.24,7.31), 1.62(1.23,2.14)$, and $8.09(6.36$, 10.29 ) for non-snorers with $\mathrm{BMI} \geq 24$, snorers with $\mathrm{BMI}<24$, and snorers with $\mathrm{BMI} \geq 24$, respectively. There was a significant additive interaction between snoring and BMI on MetS in this multi-adjusted 
Table 2 Odds Ratios and 95\% confidence intervals for the presence of MetS according to snoring status and BMI

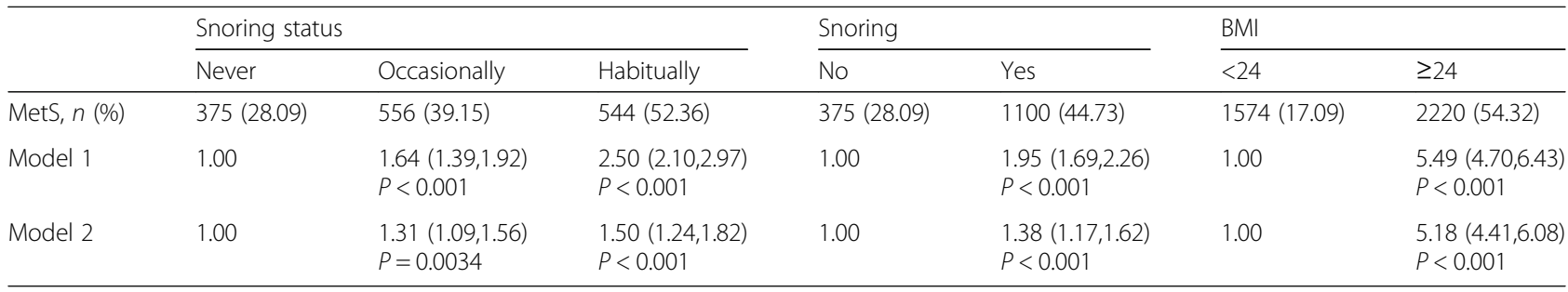

Model 1: adjusted for age and sex

Model 2: adjusted for age, sex, current smoking, alcohol consumption, marital status, physical activity level, monthly income, work type. Additionally, BMI was included as a covariate when assessing snoring status and snoring status as a covariate when assessing BMI

model (Table 4). RERI was 1.89 , suggesting that there would be 1.89 relative excess risk due to the additive interaction. We also found that $23 \%$ of the OR of being MetS exposed to both risk factors was attributable to the additive interaction, and the risk of MetS in snorers with $\mathrm{BMI} \geq 24$ was 1.37 times as high as the sum of risks in the participants exposed to a single risk factor alone. More specifically, snoring and BMI acted synergistically in the prevalence of MetS. In other words, these two factors interact to increase the risk of MetS, an effect that is more than summation of individual effects.

We further analyzed the additive interaction across different workplace, and found the inconsistent results. The additive interaction effect was significant among underground front-line workers (RERI: $6.67 \quad(1.42$, 19.42); AP: 0.41 (0.10, 0.62); S: $1.76(1.11,2.98))$ and ground workers (RERI: $2.52(0.08,5.35)$; AP: $0.32(0.01$,

Table 3 Odds Ratios and 95\% confidence intervals for the presence of metabolic syndrome components according to snoring status and BMI

\begin{tabular}{|c|c|c|c|c|c|}
\hline & \multicolumn{3}{|c|}{ Snoring status } & \multicolumn{2}{|l|}{$\mathrm{BMl}$} \\
\hline & Never & Occasionally & Habitually & $<24$ & $\geq 24$ \\
\hline \multicolumn{6}{|c|}{ High blood pressure } \\
\hline Model 1 & 1.00 & $1.18(1.02,1.37)$ & $2.04(1.73,2.40)$ & 1.00 & $2.03(1.78,2.32)$ \\
\hline Model 2 & 1.00 & $1.16(0.99,1.35)$ & $1.70(1.43,2.02)$ & 1.00 & $1.85(1.62,2.12)$ \\
\hline Model 3 & 1.00 & $1.02(0.87,1.19)$ & $1.30(1.09,1.56)$ & 1.00 & $1.73(1.51,1.99)$ \\
\hline \multicolumn{6}{|c|}{ Elevated fasting glucose } \\
\hline Model 1 & 1.00 & $1.21(0.97,1.52)$ & $2.15(1.73,2.68)$ & 1.00 & $2.16(1.78,2.63)$ \\
\hline Model 2 & 1.00 & $1.22(0.97,1.53)$ & $1.74(1.39,2.18)$ & 1.00 & $1.94(1.59,2.36)$ \\
\hline Model 3 & 1.00 & $1.09(0.85,1.37)$ & $1.39(1.09,1.79)$ & 1.00 & $1.78(1.45,2.19)$ \\
\hline \multicolumn{6}{|c|}{ Hypertriglyceridemia } \\
\hline Model 1 & 1.00 & $1.39(1.19,1.63)$ & $2.39(2.02,2.82)$ & 1.00 & $3.83(3.32,4.43)$ \\
\hline Model 2 & 1.00 & $1.33(1.13,1.55)$ & $2.07(1.75,2.46)$ & 1.00 & $3.59(3.11,4.16)$ \\
\hline Model 3 & 1.00 & $1.07(0.91,1.27)$ & $1.36(1.13,1.64)$ & 1.00 & $3.35(2.88 .3 .90)$ \\
\hline \multicolumn{6}{|c|}{ Low HDL-cholesterol } \\
\hline Model 1 & 1.00 & $1.15(0.97,1.35)$ & $1.33(1.12,1.59)$ & 1.00 & $2.37(2.04,2.76)$ \\
\hline Model 2 & 1.00 & $1.23(1.04,1.45)$ & $1.58(1.32,1.90)$ & 1.00 & $2.77(2.36,3.24)$ \\
\hline Model 3 & 1.00 & $1.08(0.90,1.29)$ & $1.16(0.95,1.42)$ & 1.00 & $2.71(2.31,3.20)$ \\
\hline \multicolumn{6}{|c|}{ Abdominal obesity } \\
\hline Model 1 & 1.00 & $1.98(1.67,2.35)$ & $4.24(3.38,5.31)$ & 1.00 & $15.55(12.61,19.17)$ \\
\hline Model 2 & 1.00 & $1.94(1.63,2.31)$ & $3.74(2.97,4.71)$ & 1.00 & $14.85(12.03,18.33)$ \\
\hline Model 3 & 1.00 & $1.52(1.25,1.83)$ & $1.97(1.51,2.56)$ & 1.00 & $13.65(11.01,16.92)$ \\
\hline
\end{tabular}

Model 1: not adjusted for other covariates

Model 2: adjusted for age and sex

Model 3: adjusted for age, sex, current smoking, alcohol consumption, marital status, physical activity level, monthly income, work type. Additionally, BMI was included as a covariate when assessing snoring status and snoring status as a covariate when assessing BMI 
Table 4 Additive interactions between snoring and BMI

\begin{tabular}{|c|c|c|c|c|c|c|}
\hline \multirow[b]{2}{*}{ Snoring } & \multirow[b]{2}{*}{ BMI } & \multicolumn{5}{|c|}{ Interaction Analysis } \\
\hline & & MetS, n (\%) & Multi-adjusted OR (95\% Cl) & RERI $(95 \% \mathrm{Cl})$ & AP $(95 \% \mathrm{Cl})$ & $\mathrm{S}(95 \% \mathrm{Cl})$ \\
\hline \multicolumn{7}{|c|}{ All workers } \\
\hline \multirow[t]{2}{*}{ No } & $<24$ & $96(13.10)$ & 1.00 & \multirow{4}{*}{$\begin{array}{l}1.89^{*} \\
(0.67,3.24)\end{array}$} & \multirow{4}{*}{$\begin{array}{l}0.23^{*} \\
(0.08,0.38)\end{array}$} & \multirow{4}{*}{$\begin{array}{l}1.37^{*} \\
(1.11,1.75)\end{array}$} \\
\hline & $\geq 24$ & $279(46.35)$ & $5.57(4.24,7.31)$ & & & \\
\hline \multirow[t]{2}{*}{ Yes } & $<24$ & $173(20.57)$ & $1.62(1.23,2.14)$ & & & \\
\hline & $\geq 24$ & $927(62.85)$ & $8.09(6.36,10.29)$ & & & \\
\hline \multicolumn{7}{|c|}{ Underground front-line } \\
\hline \multirow[t]{2}{*}{ No } & $<24$ & $9(6.16)$ & 1 & \multirow{4}{*}{$\begin{array}{l}6.67^{*} \\
(1.42,19.42)\end{array}$} & \multirow{4}{*}{$\begin{array}{l}0.41^{*} \\
(0.10,0.62)\end{array}$} & \multirow{4}{*}{$\begin{array}{l}1.76^{*} \\
(1.11,2.98)\end{array}$} \\
\hline & $\geq 24$ & $47(34.81)$ & $8.23(3.81,17.80)$ & & & \\
\hline \multirow[t]{2}{*}{ Yes } & $<24$ & $27(14.36)$ & $2.52(1.34,5.56)$ & & & \\
\hline & $\geq 24$ & $154(52.56)$ & $16.43(8.00,33.73)$ & & & \\
\hline \multicolumn{7}{|c|}{ Underground auxiliary } \\
\hline \multirow[t]{2}{*}{ No } & $<24$ & $31(13.08)$ & 1 & \multirow{4}{*}{$\begin{array}{l}0.32 \\
(-3.90,3.25)\end{array}$} & \multirow{4}{*}{$\begin{array}{l}0.04 \\
(-0.34,0.32)\end{array}$} & \multirow{4}{*}{$\begin{array}{l}1.04 \\
(0.72,1.58)\end{array}$} \\
\hline & $\geq 24$ & $89(50.57)$ & $7.36(4.51,12.03)$ & & & \\
\hline \multirow[t]{2}{*}{ Yes } & $<24$ & $68(22.97)$ & $1.97(1.23,3.15)$ & & & \\
\hline & $\geq 24$ & $350(56.36)$ & $8.65(5.71,13.10)$ & & & \\
\hline \multicolumn{7}{|c|}{ Ground workers } \\
\hline \multirow[t]{2}{*}{ No } & $<24$ & $37(16.82)$ & 1 & \multirow{4}{*}{$\begin{array}{l}2.52^{*} \\
(0.08,5.35)\end{array}$} & \multirow{4}{*}{$\begin{array}{l}0.32^{*} \\
(0.01,0.56)\end{array}$} & \multirow{4}{*}{$\begin{array}{l}1.59^{*} \\
(1.02,2.72)\end{array}$} \\
\hline & $\geq 24$ & $80(52.95)$ & $4.78(2.95,7.75)$ & & & \\
\hline \multirow[t]{2}{*}{ Yes } & $<24$ & $47(23.62)$ & $1.47(0.90,2.41)$ & & & \\
\hline & $\geq 24$ & $255(62.05)$ & $7.77(5.10,11.86)$ & & & \\
\hline \multicolumn{7}{|c|}{ Office workers } \\
\hline \multirow[t]{2}{*}{ No } & $<24$ & $19(14.62)$ & 1 & \multirow{4}{*}{$\begin{array}{l}1.10 \\
(-1.22,3.31)\end{array}$} & \multirow{4}{*}{$\begin{array}{l}0.21 \\
(-0.24,0.50)\end{array}$} & \multirow{4}{*}{$\begin{array}{l}1.35 \\
(0.77,2.76)\end{array}$} \\
\hline & $\geq 24$ & $63(45.99)$ & $3.92(2.13,7.23)$ & & & \\
\hline Yes & $<24$ & $31(19.75)$ & $1.18(0.62,2.25)$ & & & \\
\hline & $\geq 24$ & $166(56.08)$ & $5.19(2.94,9.17)$ & & & \\
\hline
\end{tabular}

*is used to highlight statistically significant $(p<0.05)$ findings

0.56); S: $1.59(1.02,2.72))$.While it was not significant among underground auxiliary workers and office workers.

\section{The result of sensitivity analysis}

As shown in the appendix table1, the demographic characteristics of the "before MI" and "after MI" group were not statistically significant (Additional file 1: Table S1). And the additive interaction is consistent in the two groups (Additional file 2: Table S2).

\section{Discussion}

Our study explored the individual effect and interactive effect between snoring and BMI on MetS. We found that both Snoring and BMI were related to Mets. We also suggest an additive interaction between snoring and BMI on MetS among employees of Datong coal mining enterprises. From the result of subgroup analysis, the additive interaction effect remained significant among underground front-line workers and ground worker.
The relationship between snoring and MetS has been explored in previous studies. Leineweber et al. reported that snoring frequency was independently associated with MetS in Swedish middle-aged women, after adjustment for potential confounding factors [13]. A cross-sectional study conducted in India also showed that snoring was significantly associated with MetS even after adjusting for age, sex, family history of diabetes, physical activities, smoking, and alcohol [14]. Sabanayagam et al. observed a positive association between snoring and MetS in a representative sample of US adults [15]. Our data suggested that snoring is significantly associated with MetS, and the association is generally in line with current evidence from other population groups in both developed and developing countries [12-18].

Furthermore, we also observed strongly positive associations between snoring status and MetS components including high blood pressure, elevated fasting glucose, hyper-triglyceridemia, and abdominal obesity. However, a Korean multi-rural communities cohort study indicated 
that snoring frequency was associated with high blood pressure, elevated glucose, and abdominal obesity, but not associated with hypertriglyceridemia and low HDL cholesterol [16]. A prospective study conducted in the United States revealed that loud snoring was a significant predictor of hyperglycemia and low HDL [18]. The discrepancies among studies might be due to differences in the measurement of snoring status, ethnics, and study design.

In current study, we also found that BMI was associated with a higher risk of MetS. Many previous studies have demonstrated this association [17, 18]. A research conducted among Mexico undergraduate students concluded that BMI was a valuable indicator to estimate MetS prevalence [19]. Yang et al. found that BMI showed a dose-response association with the increased risk of MetS [20].

To the best of our knowledge, this study is the first to examine the possible additive interaction between snoring and BMI on MetS. Results of our study revealed that the effect of snoring on MetS was significantly modified by obesity, which was consistent with an additive interaction [36]. The RERI of 1.89 means that the relative risk of having MetS in snores with $\mathrm{BMI} \geq 24$ is 1.89 higher than the sum of the independent ORs for being overweight alone and snoring alone. That is to say, the risk conferred by one of the factors is increased by the presence of the other. Therefore, snorers should pay more attention to controlling weight in order to prevent MetS and subsequent diseases.

Further stratified by workplace, we obtained more accurate information. The interaction effect was significant among underground front-line and ground workers. While it was not significant among underground auxiliary, and office workers. This may be related to some sort of occupational exposure, such as coal dust. Certainly, further studies and measurement of biomarkers of exposure are needed to determine what caused the difference.

It is beneficial to use snoring and BMI as the easily measured, low-cost and non-invasive indicators during the screening of individuals who are prone to MetS, particularly among underground front-line and ground workers. A doctor of respiratory medicine is suggested to observe the patient's BMI and metabolic syndromerelated indicators meanwhile in the diagnosis of sleep apnea syndrome, so that we can achieve early detection of patients or high-risk individuals with MetS. Because snorers with overweight or obesity have the highest risk for MetS, underground front-line workers and ground workers in this subgroup may benefit most from a targeted intervention or treatment.

Limitations of this study should also be considered. Firstly, the cross-sectional design did not allow us to infer causality. Secondly, the underreporting of snoring might lead to misclassification bias and weaken the association between snoring and MetS. Thirdly, as with any observational studies, we could not exclude the possible effects of uncontrolled or inadequately measured confounders on the results. Despite of these limitations, this is the first study, to our knowledge, to examine the additive interaction between snoring and BMI on MetS. Further prospective cohort studies with large sample sizes are necessary to reconfirm this additive interaction and to elucidate the underlying mechanism that will eventually contribute to more effective prevention strategies on MetS.

\section{Conclusion}

In conclusion, results from this cross-sectional study among Chinese coal miners confirmed previous findings on association of snoring and BMI with MetS. Moreover, this study further demonstrated an additive interaction between snoring and BMI on MetS in underground front-line and ground workers, highlighting that snorers who worked underground front-line and ground are more susceptible to the negative impact of being overweight on MetS. Preventive strategies aimed at reducing the prevalence of MetS among underground front-line and ground workers are necessary for target snorers with overweight.

\section{Additional files}

Additional file 1: Table S1. Characteristics of the study population (before and after multiple imputation). Table S2. Additive interactions evaluated by multiple imputated data set. (DOCX 28 kb)

Additional file 2: Variable Assignment Table. (DOCX $17 \mathrm{~kb}$ )

\section{Abbreviations}

AP: Attributable proportion due to interaction; BMI: Body mass index; DBP: Diastolic blood pressure; HDL-c: High-density lipoprotein cholesterol; IDF: The International Diabetes Federation; MetS: Metabolic Syndrome; MI: Multiple imputation; OSA: obstructive sleep apnea; RERI: Relative excess risk due to interaction; S: Synergy index; SBP: Systolic blood pressure; T2DM: Type 2 diabetes mellitus; TC: Total cholesterol; TG: Triglycerides; WC: Waist circumference

\section{Acknowledgments}

Thanks for the support of Graduate Student Innovation Center in Shanxi Province of China and the assistance of all interviewers and subjects who participated in our study.

\section{Funding}

This study was funded by the Natural Science Foundation of China (item no. 81473073).

\section{Availability of data and materials}

The datasets used and analysed during the current study are available from the corresponding author on reasonable request.

\section{Authors' contributions}

TW, QL, JH, CS and NQ were contributed to the study design. HZ performed the two-stage cluster stratified sampling. NQ and CW performed the experiments. YL, HW, LL, QG and YS cleared the data. YL and QG managed the data. $Y L$ was responsible for the statistical analyses, interpretation of data and drafting the manuscript. QG, LL, LQ and TW reviewed and edited the manuscript. All authors approved the final manuscript. 


\section{Ethics approval and consent to participate}

The study was approved by Shanxi Medical University Ethics Committee (HX201201). We confirm that all methods in the current study were carried out in accordance with the guidelines of the Declaration of Helsinki. Each participant provided written informed consent.

\section{Consent for publication}

Not applicable.

\section{Competing interests}

The authors declare that they have no competing interests.

\section{Publisher's Note}

Springer Nature remains neutral with regard to jurisdictional claims in published maps and institutional affiliations.

\section{Author details}

'Department of Health Statistics, School of Public Health, Shanxi Medical University, 56 Xinjiannanlu Street, Taiyuan, Shanxi 030001, People's Republic of China. ${ }^{2}$ Department of Neurosurgery, General Hospital of Datong Coal Mining Group, Datong, China. ${ }^{3}$ Department of Urology, General Hospital of Datong Coal Mining Group, Datong, China. ${ }^{4}$ Department of Epidemiology and Biostatistics, Michigan State University, East Lansing, MI 48824, USA.

Received: 13 December 2017 Accepted: 20 February 2019 Published online: 04 March 2019

\section{References}

1. Gami AS, Witt BJ, Howard DE, Erwin PJ, Gami LA, Somers VK, Montori VM. Metabolic syndrome and risk of incident cardiovascular events and death: a systematic review and meta-analysis of longitudinal studies. J Am Coll Cardiol. 2007:49(4):403-14.

2. Huh JH, Yadav D, Kim JS, Son J-W, Choi E, Kim SH, Shin C, Sung K-C, Kim JY An association of metabolic syndrome and chronic kidney disease from a 10-year prospective cohort study; 2016.

3. Zhao SC, Xia M, Tang JC, Yan Y. Associations between metabolic syndrome and clinical benign prostatic hyperplasia in a northern urban Han Chinese population: a prospective cohort study. Sci Rep. 2016;6:33933.

4. Scuteri A, Laurent S, Cucca F, Cockcroft J, Cunha PG, Mañas LR, Raso FU, Muiesan ML, Ryliškyte L, Rietzschel E. Metabolic syndrome across Europe: different clusters of risk factors. Eur J Prev Cardiol. 2015;22(4):486-91.

5. Vidigal FC, Ribeiro AQ, Babio N, Salas-Salvadó J, Bressan J. Prevalence of metabolic syndrome and pre-metabolic syndrome in health professionals: LATINMETS Brazil study. Diabetol Metabol Syndr. 2015;7(1):1-9.

6. Wang ZX, Qin RL, Li YZ, et al. A study of occupational hazards in 23 coal mine enterprises in China and their protection status.[J]. J Environ Occup Med. 2009:565-8.

7. Liang J, Tian SS, Qiao N, et al. Relationship Between Physical Activity Patterns and Metabolic Syndrome Among Male Coal Miners of Shanxi Province in China[J]. Int J Sport Nutr Exerc Metab. 2017;27(1):50-58.19.

8. Hu FB, Willett WC, Manson JAE, Colditz GA, Rimm EB, Speizer FE, Hennekens

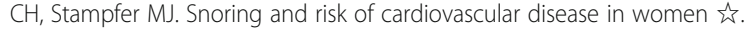
J Am Coll Cardiol. 2000;35(2):308-13.

9. Nagayoshi M, Tanigawa T, Yamagishi K, Sakurai S, Kitamura A, Kiyama M, Okada T, Maeda K, Ohira T, Imano H. Self-reported snoring frequency and incidence of cardiovascular disease: the circulatory risk in communities study (CIRCS). J Epidemiol. 2011;22(4):295-301.

10. Peppard PE, Young T, Palta M, Skatrud J. Prospective study of the association between sleep-disordered breathing and hypertension. N Engl J Med. 2000;342(19):1378-84.

11. Xiong $X$, Zhong $A, X u H$, Wang C. Association between self-reported habitual snoring and diabetes mellitus: a systemic review and meta-analysis, J Diabetes Res. 2016;2016(7):1-7.

12. Cho N, Joo SJ, Kim JK, Abbott RD, Kim JH, Kimm K, Shin C. Relation of habitual snoring with components of metabolic syndrome in Korean adults. Diabetes Res Clin Prac. 2006;71(3):256-63.

13. Leineweber C, Kecklund G, Akerstedt T, Janszky I, Orth-Gomér K. Snoring and the metabolic syndrome in women. Sleep Med. 2003;4(6):531-6.

14. Roopa M, Deepa M, Indulekha K, Mohan V. Prevalence of sleep abnormalities and their association with metabolic syndrome among Asian
Indians: Chennai urban rural epidemiology study (CURES-67). J Diabetes Sci Technol. 2010:4(6):1524-31.

15. Sabanayagam C, Zhang R, Shankar A. Markers of sleep-disordered breathing and metabolic syndrome in a multiethnic sample of US adults: results from the National Health and nutrition examination survey 2005-2008. Int J Endocrinol. 2012;2012:69-77.

16. Shin MH, Kweon SS, Choi BY, Kim MK, Chun BY, Shin DH, Lee YH. Selfreported snoring and metabolic syndrome: the Korean multi-rural communities cohort study. Sleep and Breathing. 2014;18(2):423-30.

17. Sun L, Pan A, Yu Z, Li H, Shi A, Yu D, Zhang G, Zong G, Liu Y, Lin X: Snoring, inflammatory markers, Adipokines and metabolic syndrome in apparently healthy Chinese. PLoS One 2011, 6(11):436-436.

18. Troxel WM, DJB KAM, Kip KE, Strollo PJ, Hall M, Drumheller O, Reis SE. Sleep symptoms predict the development of the metabolic syndrome. Sleep. 2010:33(12):1633-40.

19. Murguíaromero M, Jiménezflores R, Villalobosmolina R, Mendozaramos MI, Reyesreali J, Sigristflores SC, Méndezcruz AR. The body mass index (BMI) as a public health tool to predict metabolic syndrome. Open J Prevent Med. 2012;2(2):59-66.

20. Yang FY, Wahlqvist ML, Lee MS. Body mass index (BMI) as a major factor in the incidence of the metabolic syndrome and its constituents in unaffected Taiwanese from 1998 to 2002. Asia Pac J Clin Nutr. 2008:17(2):339-51.

21. Fletcher EC. Sympathetic over activity in the etiology of hypertension of obstructive sleep apnea. Sleep. 2003:26(1):15-9.

22. Marrone O, Riccobono L, Salvaggio A, Mirabella A, Bonanno A, Bonsignore MR. Catecholamines and blood pressure in obstructive sleep apnea syndrome. Chest. 1993;103(3):722-7.

23. Marshall S, Garvey WT, Traxinger RR. New insights into the metabolic regulation of insulin action and insulin resistance: role of glucose and amino acids. Faseb J Official Public Feder American Soc Experiment Biol. 1991;5(15):3031-6.

24. Rosen ED, Spiegelman BM. Adipocytes as regulators of energy balance and glucose homeostasis. Nature. 2011, 444(7121):847-53.

25. Ip MS, Lam KS, Ho C, Tsang KW, Lam W. Serum leptin and vascular risk factors in obstructive sleep apnea. Chest. 2000;118(3):580-6.

26. Harsch IA, Konturek PC, Koebnick C, Kuehnlein PP, Fuchs FS, Pour SS, Wiest $\mathrm{GH}$, Hahn EG, Lohmann T, Ficker JH. Leptin and ghrelin levels in patients with obstructive sleep apnoea: effect of CPAP treatment. Eur Respir J. 2003:22(2):251-7.

27. Igarashi N, Tatsumi K, Nakamura A, Sakao S, Takiguchi Y, Nishikawa T, Kuriyama T. Plasma orexin-a levels in obstructive sleep apnea-hypopnea syndrome. Chest. 2003;125(5):1963-4.

28. Pillar G, Shehadeh N. Abdominal Fat and Sleep Apnea: the Chicken or the Egg? Diabetes Care. 2008;31(Suppl 2):e62.

29. Knol MJ, Van dTI, Grobbee DE, Numans ME, Geerlings MI. Estimating interaction on an additive scale between continuous determinants in a logistic regression model. Int J Epidemiol. 2007;36(5):1111.

30. Andersson T, Alfredsson L, Källberg H, Zdravkovic S, Ahlbom A. Calculating measures of biologic interaction. Eur J Epidemiol. 2005;20(7):575-9.

31. Fomenko DV, Gorokhova LG, Panev NI, Kazitskaia AS, Bondarev OI. Clinical and experimental studies of metabolic response to chronic exposure to coal dust. Med Tr Prom Ekol. 2011;2:15.

32. Zhang X, Sun Z, Zhang X, Zheng L, Li J, Liu S, Xu C, Li J, Zhao F, Hu D. Prevalence of metabolic syndrome in Han and Mongolian rural population with hypertension. J Int Med Res. 2007;35(5):597-9.

33. Wolin K. Guidelines for data processing and analysis of the international physical activity questionnaire (IPAO) — short and long form; 2005; 2008

34. Panoulas VF, Ahmad N, Fazal AA, Kassamali RH, Nightingale P, Kitas GD, Labib M. The inter-operator variability in measuring waist circumference and its potential impact on the diagnosis of the metabolic syndrome. Postgrad Med J. 2008:84(993):344-7.

35. Alberti KG, Eckel RH, Grundy SM, Zimmet PZ, Cleeman Jl, Donato KA, Fruchart JC, James WP, Sidney C, Jr S. Harmonizing the metabolic syndrome: a joint interim statement of the international diabetes federation task force on epidemiology and prevention; National Heart, Lung, and Blood Institute; American Heart Association; world heart federation; international association for the study of obesity. Circulation. 2009:120(16):1640-5

36. Rothman KJ, Greenland S, Walker AM. Concepts of interaction. Am J Epidemiol. 1980:112(4):467-70 